\title{
Smart Socks System as an Equipment to Analyze Temporal Parameters of Human Gait and Running
}

\author{
Aleksandr Oks', Aleksey Katashev², Edgars Bernans ${ }^{3}$, Valters Abolins ${ }^{3}$ \\ ${ }^{1}$ Riga Technical University, Institute of Textile and Technology, Riga, Latvia. \\ ${ }^{2}$ Riga Technical University, Institute of Biomedical Engineering and Nanotechnology, Riga, Latvia. \\ ${ }^{3}$ Latvian Academy of Sport Education, Laboratory of Physical Capacity, Brivibas street 333, Riga, Latvia \\ E-mail:aleksandrs.okss@rtu.lv
}

\begin{abstract}
The aim of present study was to demonstrate usability of the recently developed "Smart Socks" System for analysis of locomotion temporal parameters. Smart socks system exploits pressure sensors which can be knitted directly in the garment, thus providing minimal discomfort for user. Two types of locomotion were analysed: walking and running. Experienced athletes took part in the experiment to perform movements in the controlled conditions in laboratory. The research demonstrated that temporal accuracy of Smart Sock system is acceptable for practical purposes. Data, provided by the system could distinguish heel strike and non-heel strike run and walk modes. More data is required for deeper analysis and interpretation of obtained temporal parameters and for development of recommendations for athletes and coaches.
\end{abstract}

Keywords: smart socks, running, walking, biomechanics.

\section{INTRODUCTION}

Development of useful wearable motion capture tool for sport purposes is a complicated task. Athletes are moving with a continuously changing velocity and direction, therefore, adaptive instrument which provides on-line locomotion monitoring is required.

Recently developed wearable "Smart socks" system [16] provides potential solution for acquisition of human locomotion spatio-temporal parameters at walking, running, jogging and other activities, that involve movements of the feet. The wearability of the system allows record data during physical activity in natural conditions both indoor and outdoor. Another important feature, that distinguish the proposed system from commercially available accelerometric devices is an ability to monitor the contact between feet sole and ground. The system consists of a pair of specially designed socks with integrated knitted pressure sensors and conductive lines and a data acquisition block, that communicates via bluetooth with computer or other kind of electronic gadgets. The socks are easy to wear and causes minimal discomfort for athlete.

Each sock has five sensors which can be arranged and knitted in different parts of the sock according to the specific demands of locomotion monitoring. Sensors can be used to determine different spatio - temporal parameters of running and walking, including cadence and strike pattern [16].

There is three types of strike pattern at running: heel strike, midfoot and forefoot strike [4]. Heel strike is a pattern when rear part of the foot makes contact with ground surface first (it has also been called as rear foot strike) [15]. In midfoot strike it's the middle part of foot which touches the running surface first and the front of the foot land first in forefoot strike [11]. Each of them has it's own advantages and disadvantages [7]. Runners most often are choosing their favourite strike pattern by a natural way or study which one suits them best of all $[5,9]$.

Study of the most appropriate strike pattern has great interest from the scientific point of view. Number of research has been done to find the most efficient running technique that helps to avoid athlete's injuries [3]. Typically these patterns have been analysed by measuring ground reaction forces (GRF) in running. It that case it is possible to determine the pattern of foot strike and analyse the volume and parameters of different GRF components $[1,14]$.

Smart sock system does not allow to analyse GRF directly, but strike patterns still may be determined using temporary signals from five foot plantar pressure sensors, for example, by analysis of the sensor's activation timing.

The strike timing information, obtained by a trained person in real time could be immediately used for instant movement pattern correction in the training process or even in competitions [2]

In walking, different patterns of foot strike are 
not defined in detail, as compared with running [10, 13]. In gait analysis, a stride is generally subdivided into a stance and a swing phase. More attention is paid for measurements of such parameters as step time and frequency, or cadence, foot - ground contact time as well as to analysis of different gait phases [12].

Measurements of the step time allows to analyse and compare differences in these variables between both legs. It's also important to define movement asymmetry [6]. Step frequency can be defined as the count of steps, performed over the certain period of time [17, 18]. Contact time of foot is defined as a period of time from the moment when foot makes first contact with ground surface until the moment when it takes off [8].

The purpose of the present work is to evaluate usability of the developed "Smart socks" for the evaluation of athletes' locomotions at race walking and running.

\section{MATERIALS AND METHODS}

Volunteer participants performed walking and running on treadmill and also on casual surface indoor. Running was performed by an experienced distance runner. The running velocity was $6 \mathrm{~km} / \mathrm{h}$. Walking velocity was $3 \mathrm{~km} / \mathrm{h}$. Participants had to wear the smart socks system, size of socks was adapted individually.

The placement of foot sensors is shown in Fig. 1 . Sensors A and B are placed in front, C and D -in the middle, and sensor $\mathrm{E}$ is placed in the rear part of the foot.

Increase of the plantar pressure on the sensors lead to the decrease in the electric resistance of the sensors. The resistance of the sensors was measured by custommade data acquisition system with the sampling rate of $15 \mathrm{~Hz}$. The resistance reciprocal value was calculated and normalised to form arbitrary sensor pressure signal.

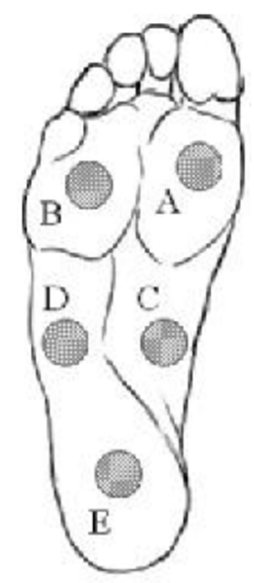

Fig.1. Placement of the sensors [16]

Procedure for determination of spatio-temporal parameters

In order to determine the foot strike phases, each step should be "recorded" by all of the sensors. When the output signal values of all five sensors are summed together, ground contact phase may be detected. Fig. 5 demonstrates $4 \mathrm{~s}$ long running pattern fragment, 5 strides and 5 contact phases are clearly visible..

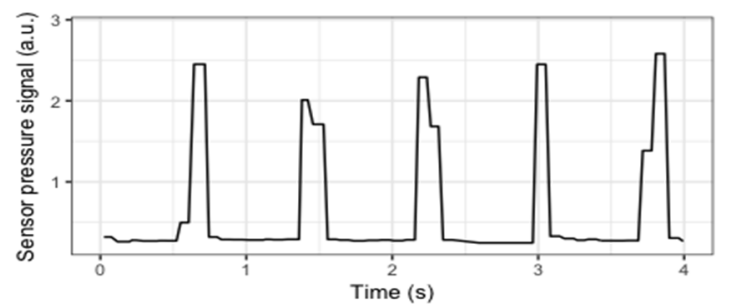

Fig.2. Signals of all sensors in running locomotion.

When running or walking with heel strike pattern, heel hits the ground first, The rest of the foot follows afterward, so the sensor E activates earlier than rest of the sensors. Sensor E also reaches the maximum value earlier than sensors $A$ and B, placed in front of the foot. Sensors C and D, that are placed in the middle of the foot, could perform differently in dependence of the foot landing patterns. These sensors are not affect heel strike pattern detection.

When running with other strike pattern, the sequence of sensors activation will be different: if sensor $E$ reaches its maximum value at the same time as other sensors or later, then it is not a heel strike pattern.

Based on these observations algorithm to determine if the person is running or walking with heel strike pattern was created.

\section{RESULTS AND DISCUSSION}

When running with heel strike, sensor $\mathrm{E}$ (or the heel sensor) reaches the highest value before sensors A and B (or their sum). It is demonstrated at the Fig. 3 and Fig.4.

At Fig.3, heel sensor reaches its highest value in 0.03 s from the beginning of the cadence, but $\mathrm{A}$ and $\mathrm{B}$ (or the forefoot sensors) reaches the highest value in $0.12 \mathrm{~s}$.

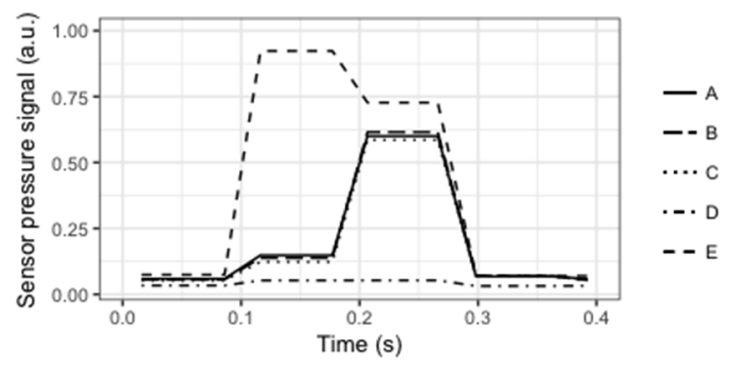

Fig.3. Heel strike running

At Fig.4, heel sensor reaches its highest value in $0.03 \mathrm{~s}$ but sum of forefoot sensors reaches the highest value in $0.12 \mathrm{~s}$. Its clearly visible, that heel sensor reaches the highest value before forefoot sensors in Fig.4. and Fig.5. 


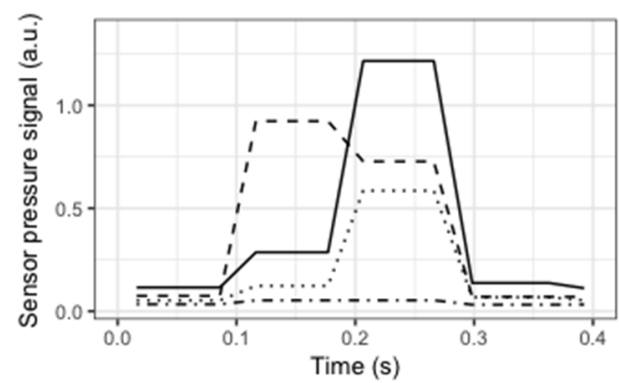

Fig.4. Heel strike running

This means that running was done with a heel strike. When running with full feet striking the ground the forefoot sensors and heel sensor got the highest value at the same time (Fig.5. and Fig.6).

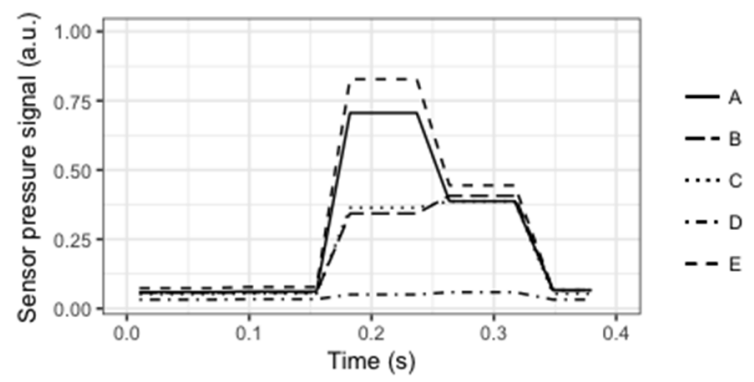

Fig.5. Running non heel strike pattern

In this case it's not clear, if running was done with a midfoot strike or forefoot strike. Despite this fact it's clear that running wasn't done with heel strike.

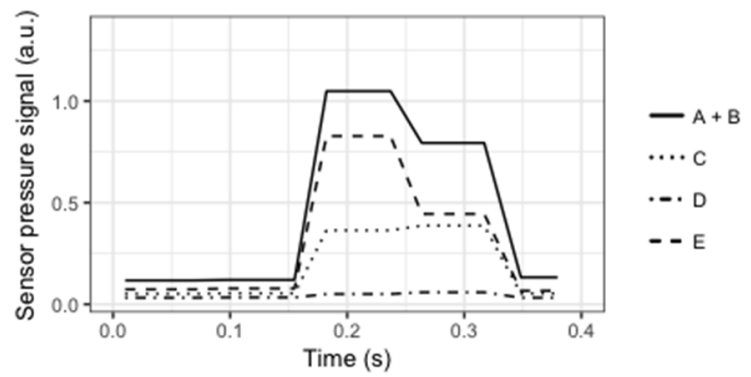

Fig.6. Running non heel strike pattern

When walking (Fig.7.) the sensors get their highest values similar to heel strike running - heel sensor gets the highest value faster than forefoot sensors or their sum (Fig.8.). At Fig.7, heel sensor reaches its highest value in $0.21 \mathrm{~s}$ but forefoot sensors in $0.29 \mathrm{~s}$ and $0.45 \mathrm{~s}, \mathrm{~A}$ and $\mathrm{B}$ respectively.

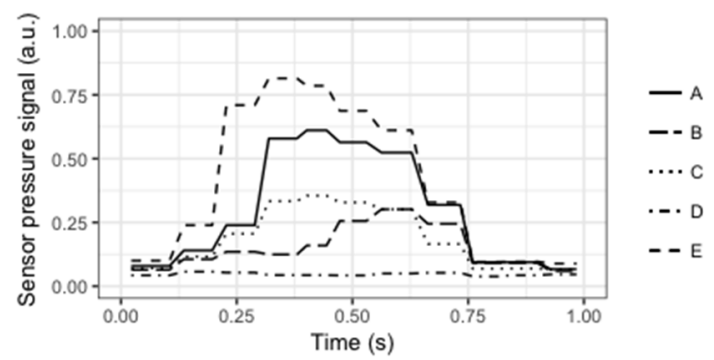

Fig.7. Walking pattern

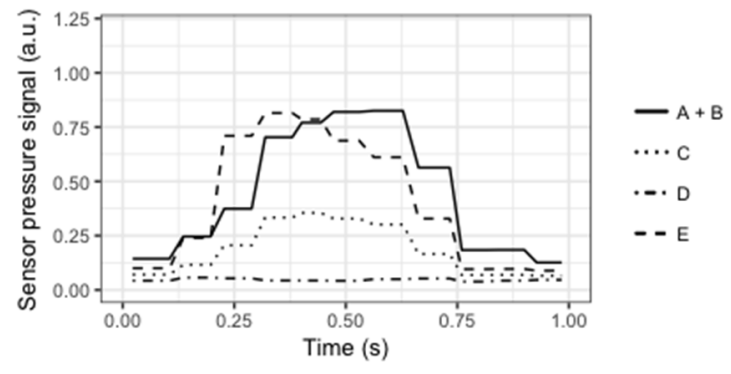

Fig.8. Walking pattern

\section{CONCLUSION}

Smart socks system is an applicable tool to identify several spatio-temporal parameters of human gait and running.

System works accurate with relatively slow running and walking velocity, moving in higher velocity need to be researched.

The temporal resolution of the of Smart Sock System is acceptable for strike pattern analysis purposes. The system could be used for determination of gait/run temporal parameters and differentiation of the mode of locomotion.

More detailed research is required for elaboration, analysis and interpretation of other biomechanical parameters as well as for development of the recommendations to athletes and coaches.

\section{ACKNOWLEDGEMENT}

The work was supported by the European Regional Development Fund project "Synthesis of textile surface coating modified in nano-level and energetically independent measurement system integration in smart clothing with functions of medical monitoring”, agreement 1.1.1.1/16/A/020

\section{REFERENCES}

[1] Cavanagh, P. R., \& Lafortune, M. A. Ground reaction forces in distance running. Journal of biomechanics, 13(5), 1980, pp 397-406.

[2] Crowell, H. P., Milner, C. E., Hamill, J., \& Davis, I. S. Reducing impact loading during running with the use of real-time visual feedback. journal of orthopaedic \& sports physical therapy, 40(4), 2010, 206-213.

[3] Daoud, A. I., Geissler, G. J., Wang, F., Saretsky, J., Daoud, Y. A., \& Lieberman, D. E.. Foot strike and injury rates in endurance runners: a retrospective study. Med Sci Sports Exerc, 44(7), 2012, 1325-1334.

[4] Fellin, R. E., Rose, W. C., Royer, T. D., \& Davis, I. S. Comparison of methods for kinematic identification of footstrike and toe-off during overground and treadmill 
running. Journal of Science and Medicine in Sport, 13(6), 2010, 646-650.

[5] Giandolini, M., Poupard, T., Gimenez, P., Horvais, N., Millet, G. Y., Morin, J. B., \& Samozino, P.. A simple field method to identify foot strike pattern during running. Journal of biomechanics, 47(7), 2014, pp 1588-1593. ISO 690.

[6] Gregg, R. D., Dhaher, Y. Y., Degani, A., \& Lynch, K. On the mechanics of functional asymmetry in bipedal walking. IEEE Transactions on Biomedical Engineering, 59(5), 201[7] Horvais, N., \& Samozino, P. Effect of midsole geometry on foot-strike pattern and running kinematics. Footwear Science, $5(2), 2013,81-89$.

[7] Horvais, N., \& Samozino, P. Effect of midsole geometry on footstrike pattern and running kinematics. Footwear Science, 5(2), 2013, 81-89.

[8] Hreljac, A., \& Marshall, R. N. Algorithms to determine event timing during normal walking using kinematic data. Journal of biomechanics, 33(6), 2000, 783-786.

[9] Kasmer, M. E., Liu, X. C., Roberts, K. G., \& Valadao, J. M. Footstrike pattern and performance in a marathon. International journal of sports physiology and performance, 8(3), 2013, 286292.

[10] Keller, T. S., Weisberger, A. M., Ray, J. L., Hasan, S. S., Shiavi, R. G., \& Spengler, D. M. Relationship between vertical ground reaction force and speed during walking, slow jogging, and running. Clinical Biomechanics, 11(5), 1996, 253-259.

[11] Larson, P., Higgins, E., Kaminski, J., Decker, T., Preble, J., Lyons, D., ... \& Normile, A. Foot strike patterns of recreational and sub-elite runners in a long-distance road race. Journal of sports sciences, 29(15), 2011, 1665-1673.

[12] Lohman, E. B., Sackiriyas, K. S. B., \& Swen, R. W. (2011). A comparison of the spatiotemporal parameters, kinematics, and biomechanics between shod, unshod, and minimally supported running as compared to walking. Physical Therapy in Sport, 12(4), 2011, 151-163.

[13] Masani, K., Kouzaki, M., \& Fukunaga, T. Variability of ground reaction forces during treadmill walking. Journal of Applied Physiology, 92(5), 2002, 1885-1890.

[14] Nilsson, J., \& Thorstensson, A. Ground reaction forces at different speeds of human walking and running. Acta Physiologica, 136(2), 1989. pp 217-227.

[15] Ogueta-Alday, A., Rodríguez-Marroyo, J. A., \& GarcíaLópez, J. Rearfoot striking runners are more economical than midfoot strikers. Med Sci Sports Exerc, 46(3), 2014, 580-5.

[16] Oks A., Katashev A et al. Development of Smart Sock System for Gate Analysis and Foot Pressure Control. IFMBE Proceedings, 57, 2016, pp. 466-469.

[17] Rowlands, A., Stone, M. R., \& Eston, R. G. Influence of speed and step frequency during walking and running on motion sensor output. Medicine and science in sports and exercise, 39(4), 2007, 716.

[18] Zatsiorky, V. M., Werner, S. L., \& Kaimin, M. A.. Basic kinematics of walking. Step length and step frequency. A review. The Journal of sports medicine and physical fitness, 34(2), 1994, 109. 